\title{
Utilizing Advanced Technologies to Augment Pharmacovigilance Systems: Challenges and Opportunities
}

\author{
David John Lewis ${ }^{1,2}$. John Fraser McCallum ${ }^{3}$
}

Received: 16 August 2019 / Accepted: 4 November 2019 / Published online: 28 December 2019

(c) The Author(s) 2019

\begin{abstract}
There are significant challenges and opportunities in deploying and utilizing advanced information technology (IT) within pharmacovigilance (PV) systems and across the pharmaceutical industry. Various aspects of PV will benefit from automation (e.g., by improving standardization or increasing data quality). Several themes are developed, highlighting the challenges faced, exploring solutions, and assessing the potential for further research. Automation of the workflow for processing of individual case safety reports (ICSRs) is adopted as a use case. This involves a logical progression through a series of steps that when linked together comprise the complete work process required for the effective management of ICSRs. We recognize that the rapid development of new technologies will invariably outpace the regulations applicable to PV systems. Nevertheless, we believe that such systems may be improved by intelligent automation. It is incumbent on the owners of these systems to explore opportunities presented by new technologies with regulators in order to evaluate the applicability, design, deployment, performance, validation and maintenance of advanced technologies to ensure that the PV system continues to be fit for purpose. Proposed approaches to the validation of automated PV systems are presented. A series of definitions and a critical appraisal of important considerations are provided in the form of use cases. We summarize progress made and opportunities for the development of automation of future systems. The overall goal of automation is to provide high quality safety data in the correct format, in context, more quickly, and with less manual effort. This will improve the evidence available for scientific assessment and helps to inform and expedite decisions about the minimization of risks associated with medicines.
\end{abstract}

Keywords Pharmacovigilance $\cdot$ Information technology $\cdot$ Emerging technology $\cdot$ Artificial intelligence $\cdot$ Automation

\section{Background}

Recent technological advances in the areas of artificial intelligence and intelligent automation have profound implications for medicine and in the discovery development and post-marketing phases of the life cycle of pharmaceutical medicines. In comparison to other business sectors, the pharmaceutical industry has been relatively slow to adopt

David John Lewis

david-1.lewis@novartis.com

1 Novartis Global Drug Development, Novartis Pharma GmbH, Oeflinger Strasse 44, D-79664 Wehr, Germany

2 Department of Pharmacy, Pharmacology and Postgraduate Medicine, University of Hertfordshire, Hatfield, Hertfordshire AL10 9AB, UK

3 Product Development Safety Risk Management, Roche Products Limited, 6 Falcon Way, Shire Park, Welwyn Garden City, Hertfordshire AL7 1TW, UK artificial intelligence and automation. As a direct consequence the industry has struggled not to fall behind in terms of the implementation of intelligent automation related to other sectors (e.g., finance). Pharmacovigilance (PV) is the science of monitoring the effects of medicinal products with the aim of identifying and evaluating potential adverse reactions [1]. Regulations and guidelines are in place to govern PV conducted by pharmaceutical companies [2-4]. PV systems are supported by secure closed relational databases. These databases are often linked to a data warehouse and advanced tools to enable the retrieval reporting and visualization of data in support of signal detection and risk management $[5,6]$. 


\section{Introduction}

There is a wealth of regulations concerning the obligations incumbent upon Sponsors of clinical trials [7, 8] and Marketing Authorization Holders (MAHs) for marketed medicinal products $[2,4]$. These obligations mandate the collection of large and growing volumes of safety data [4], with some MAHs conducting over one million transactions involving individual case safety reports (ICSRs), medication errors, product quality complaints, and exposures to medicines during pregnancy. ICSRs comprise records of single patients from various sources (e.g., healthcare professionals, patients and carers) which are collected, collated, formatted and assessed according to a standard process [9-12]. Figure 1 shows a typical flow diagram to illustrate the processing ICSRs within a MAH.

This has challenged established business practices. It provides an opportunity to determine if, and where, new technology may add value to the traditional, paper-based PV processes. The practical implementation and deployment of advanced information technology (IT) will have implications for regulators and may affect areas involving the use of such data and an individual's right to privacy. Figure 2 shows, at a conceptual level, these distinct areas and this paper intends to position itself at their intersection.

The TransCelerate Intelligent Automation project has been set-up to address some of the challenges [13]. Our aim is to categorize the challenges and opportunities in the context of the PV system with a view to maintain a coherent overview, using simple language to facilitate understanding.
We will provide a series of considerations for the applicability for new IT, where we explain the technology and show its applicability within specific domains of the PV system (Table 2). Proposals will be made for the classification and validation of new IT and finally we will consider areas for further research.

As we progress through this paper, there are several key points to remember:

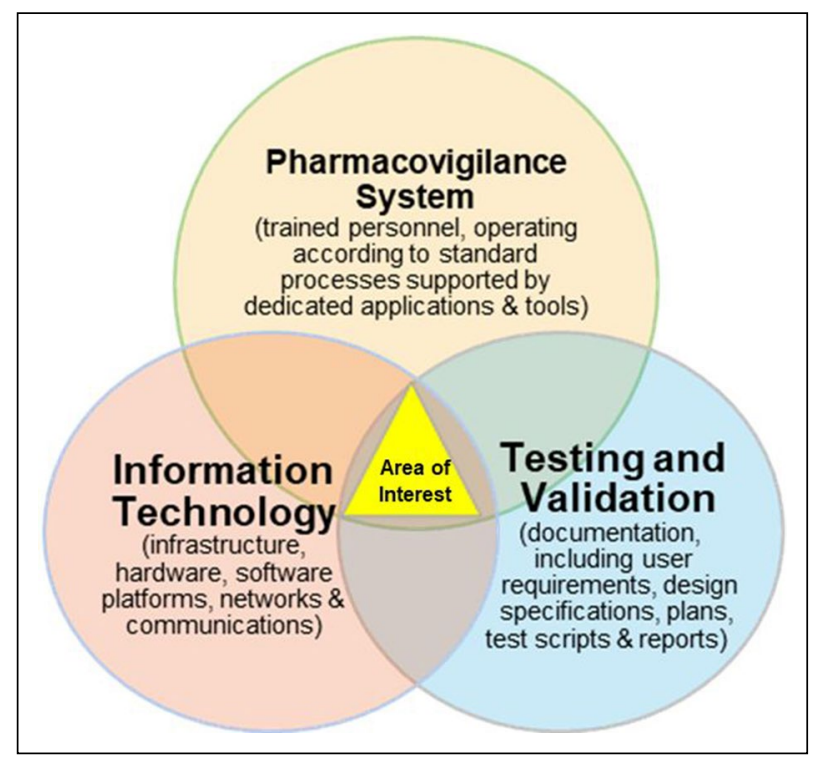

Figure 2. Conceptual Diagram Showing the Different Entities Relating to Automation in PV Systems.

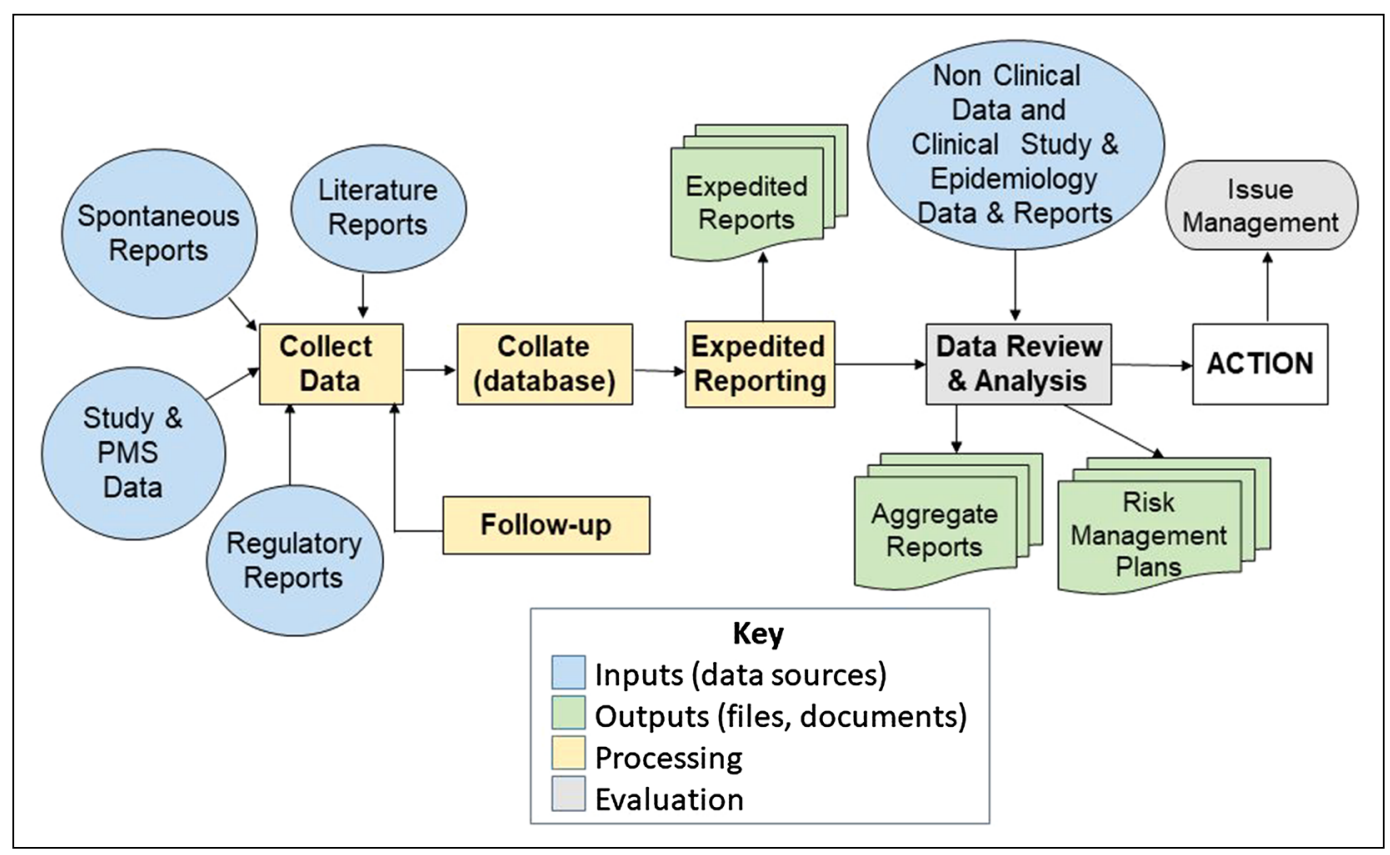

Figure 1. Typical Process for the Management of Individual Case Safety Reports Within a Marketing Authorization Holder. 
1. Significant challenges (e.g., need for large volumes of data to aid automated signal detection using disproportionality statistics) and opportunities exist (e.g., the availability of multiple methods to support disproportionality-based signal detection) when designing, deploying, and utilizing advanced IT within PV systems.

2. Rapid development of IT will outpace the regulations applicable to PV systems; validation of advanced technologies is essential to ensure that these systems remain fit for purpose (e.g., scalable to future standardized knowledge ontologies and source data) [12]

3. Automation of PV processes can provide high quality safety data in the correct format, in context, more quickly, and with less manual effort, thereby improving the evidence available for timely scientific assessment.

\section{Pharmacovigilance Systems Operated by Marketing Authorization Holders}

The PV system within a MAH is an important contributor to the evidence base required for the approval of a licensed medicine. Safety, quality, and efficacy must be established in order for a product license to be granted. PV systems operated by MAHs must be managed according to Good Pharmacovigilance Practice standards and, under applicable law, must include at least the following capabilities: $[2,3,14,15]$

1. To perform ongoing benefit-risk assessment throughout the life cycle of the medicinal product

2. To collect, collate, and manage case reports of adverse reactions (including overdose, misuse, abuse, addiction, or tolerance), reports of exposures to medicines during pregnancy, reports of medication errors, and suspected counterfeit or substandard medicinal products

3. To report both ICSRs and in aggregate [periodically according to legal obligations to the Health Authorities and other stakeholders within countries and regions (e.g., healthcare professionals, ethics committees, patients, carers, etc.)]

4. To conduct safety monitoring within clinical trials according to Good Clinical Practice standards, ensuring that important safety information is documented and reported

5. To design, implement, and conduct post-authorization safety studies (PASS) to investigate, identify, characterize, and/or quantify a safety hazard; to confirm the safety profile of a medicine; and/or to measure the effectiveness of risk-management measures

6. To identify safety signals causally associated with medicinal products throughout clinical development and in the post-marketing phase
7. To prepare a Risk Management Plan and/or Risk Evaluation and Mitigation Strategy with additional Risk Minimization Materials where required

8. To monitor the effectiveness of risk minimization measures and to adjust or amend materials to reduce risks to patients

9. To identify if there are product quality problems in medicines resulting in adverse drug reactions (ADRs) and, more generally, support the identification of medicine quality issues

10. To apply resulting information from pharmacovigilance for the benefit of public health programs, individual patients, and national medicines policies and treatment guidelines

11. To develop and maintain drug utilization information

12. To identify issues associated with unregulated prescribing and dispensing of medicines

The WHO also sets the expectation that a PV system must enable the provision of effective communication on aspects related to medicine safety, including dispelling unfounded rumors of toxicity attributed to medicines and/or vaccines $[16,17]$.

\section{Current Uses of Information Technology in Pharmacovigilance: Rule-Based Static Systems}

Current PV systems rely on binary-logic based algorithms to aid safety data management. Some examples of programmatic algorithms in rule-based static systems are provided in Table 1. These user-managed rules apply consistent, objective expert knowledge in a standardized manner; the results of algorithmic data processing are therefore known and understood. This approach takes best performance and converts it into the standard process. Validation of these rules follows traditional methods, such as script-based user acceptance testing (UAT). Five (5) PV system domains are defined in the European Good Pharmacovigilance Practice Annex 1 [1] and briefly described here:

- Quality (management) system (QMS) for the PV system: The organizational structure, responsibilities, procedures, processes, and resources of the PV system as well as appropriate resource management, compliance management, and record management. The QMS is part of the PV system [18].

- Risk management system: A set of PV activities and interventions designed to identify, characterize, prevent, or minimize risks relating to a medicinal product, including the assessment of the effectiveness of those activities and interventions [19]. 
Table 1. Algorithmic Functions in Rule-based Static Systems.

\begin{tabular}{lc}
\hline Algorithm Purpose & Use Case \\
\hline Association & Quality Management System (QMS): Detection of data outliers in clinical trials or post-marketing \\
& studies (e.g., abnormal hematology results indicative of a blood dyscrasia, changes of heart rate or \\
rhythm, which may represent an adverse reaction to medical treatment) \\
Detection of patients with undiagnosed Gilbert's syndrome (by careful assessment of liver function \\
test results and evaluation of any associated signs or symptoms using single-patient profiles) \\
ICSRs: Duplicate checking of ICSRs (identification of potential duplicate reports-for example, \\
the same patient reported by the attending doctor and the pharmacist that dispensed the medicinal \\
product by identifying links between selected data fields such as age, gender, start and stop dates \\
of medical treatment, adverse reaction terms, outcome, etc.) \\
Signal management: Prioritization of medical review of adverse event terms using statistical dis- \\
proportionality scores which exceed a pre-determined threshold level (counts above the threshold \\
represent an excess of observations of a particular adverse event versus the expected value) \\
ICSRs: Processing and management of ICSRs, e.g., workflow with prescribed routing of ICSRs for \\
processing (see Introduction and Fig. 1 for details) \\
Risk management: Identification of potential risks (an untoward occurrence for which there is some \\
basis for suspicion of an association with the medicinal product of interest but where this associa- \\
tion has not been confirmed) versus identified risks (an untoward occurrence for which there is \\
adequate evidence of an association with the medicinal product of interest) [1] \\
Aggregate reporting: Categorizing ICSRs within a Periodic Safety Update Report (PSUR), e.g., seri- \\
ous versus non-serious and reported by healthcare professional versus reported by a patient
\end{tabular}

- Management of ICSRs: Collection, collation, processing, and assessment of safety data to standardize the format and content of a relational database used for the reporting of one or several suspected adverse reactions to a medicinal product that occur in a single patient at a specific point of time [20].

- Aggregate reporting: Periodic reports summarizing safety data received over a fixed-term for a specified medicinal product, sometimes including a detailed comparison with the cumulative safety data for the product. Examples include the Periodic Benefit Risk Evaluation Report (PBRER) [21].

- Signal management: A set of activities performed to determine whether, based on an examination of ICSRs, aggregated data from active surveillance systems or studies, scientific literature information or other data sources, there are new risks associated with an active substance or a medicinal product or whether known risks have changed, as well as any related recommendations, decisions, communications, and tracking [22].

\section{Artificial Intelligence (AI)-Informed Static Systems}

Artificial Intelligence (AI) is an all-embracing term for the simulation of human intelligence processes by computer systems. AI encompasses a wide range of technologies including following rules, reasoning (using rules to reach approximate or definite conclusions), learning, and self-correction. These technologies can be seen in a number of PV system domains including ICSRs [20], aggregate reporting, risk management, signal management, and the QMS supporting the PV system. The arguments in favor of the utility of AI that make this technology applicable to multiple domains within pharmacovigilance systems are based initially, at least, on the elimination of human error, standardization of processes, expediting processing cycle times, and reducing manual effort. A trend towards adoption of AI-informed processing is evident where the results are largely known and understood. Validation is based on the correlation of the human-processed data with the results from the AI-informed process; a use case could be use of machine learning to code terms or products where such terms are ambiguous, have errors, abbreviations, or use slang terms.

\section{Putative Adoption of Dynamic Systems with Binary or Retrospective Outcome or Predictive Outcome}

Dynamic systems can be integrated into PV systems and produce binary (or retrospective) outcomes in which the results make sense to a human and the method is understood by a human. Dynamic systems can also be used to produce predictive outcomes in which the results make sense to a human and the method can be comprehended by a human. PV systems are invariably dynamic; for this reason, implementation and validation is problematic. At this time, there is no clear regulatory guidance, nor is there a consensus of approach concerning the adoption of automation in this domain. One use case would be intelligent workflow for the processing of ICSRs. In this setting, a company could employ automation to direct designated staff to conduct specific tasks and which may be semi-automated. This would facilitate processing by helping to balance in real time the amount and priority 
of the work to the availability and skill level of the people supporting the process, leading to improvements in quality and compliance of the output.

\section{Future Pharmacovigilance Systems: Adoption of Emerging Technologies}

Consideration of emerging technologies will be on a caseby-case basis. While it is speculative to pre-determine the applicability of such technologies to PV systems, we are aware of some examples of pilot testing.

Emerging technologies facilitating innovation in PV are many and complex. While the IT professionals responsible for creating these technologies understand their mechanics, it is not always clear to the professionals attempting to bring these to bear on the science and process of PV. We describe some IT emerging technologies and how they can be used in PV in Table 2. Lengthy and detailed technical definitions are available elsewhere [23, 24].

\section{Ethical and Policy Implications of Automation Within PV Systems}

We recognize that regulations are in place concerning the processing of personal data. The science of PV relies on the consistent and diligent application of high-quality data management techniques which can be improved by automation. The primary purpose of PV is to reduce or minimize risks, which in turn contributes to optimizing the use of medicinal products. In general, safety evaluation is agnostic of personal data; hence, there is a limited likelihood of any invasion of privacy or risk of breach of confidentiality. Nevertheless, the use of automation in PV systems must be very carefully assessed to ensure compliance with data privacy regulations $[45,46]$. As an obligation related to the QMS for the PV system, a company would need to consider the degree of human oversight necessary to provide a trusted, reliable, consistent, and valid output.

Beyond the technological considerations, MAHs will need to consider the procedural, organizational, and capability changes required to implement more advanced intelligent automation solutions. Novel technologies provide significant opportunities to enhance the conduct of PV:

- Novel methodologies to demonstrate the oversight of capability of the PV system to protect the wellbeing of patients

- Opportunity to question underlying assumptions and potentially eliminate traditional process steps, such as triage, to improve overall quality and performance of the PV system

- Re-examine resourcing in PV: Implementation of intelligent automation technologies is in itself a sourcing strategy and, with sufficient scale, provides an opportunity to elevate quality, efficiency, capacity, and performance in PV

Beyond validation of new IT, there are also other considerations that will be critical to its implementation:

- The right of all individuals to privacy and to protection of personal data concerning health matters. Regulations exist at both regional and national levels in order to safeguard the privacy of safety data from which an individual may be identified $[45,46]$. The European General Data Protection Regulation (GDPR), for example, applies to organizations that control or process personal data of European Union (EU) residents whether or not they have a physical presence within the EU.

- Skills and competencies of individuals working within the PV system. Currently these are built around established methods but use of machine learning (for example) will lead to the disruption of the traditional PV and IT interfaces [26, 27, 40, 42]. Already, there is evidence that AI can equal or exceed human performance in various areas of medical science [47-51].

- Change management with impacted functions and individuals [52]. The PV system spans many areas beyond the safety department of the MAH, and the use of new IT will cause impact to many upstream and downstream stakeholders. It is likely that such implementation will result in unforeseen challenges but produce equally unforeseen opportunities to improve the entire PV system.

- Impact of intelligent automation on Business Continuity planning. With increasing levels of automation, it may be prudent to focus efforts on resumption of automated activities and move away from manual workarounds. However, it will be important to maintain flexibility to comply with the regulations surrounding PV and continue vigilance activities during an interruption to protect patient safety.

- Preparation, conduct, and completion of corrective actions and preventative actions (CAPAs) resulting from audit and inspection. Certain aspects of intelligent automation are not human intelligible. It is vital in audit and inspection to provide justifiable evidence that the automation deployed is fit for purpose, and that the MAH has demonstrable oversight of their PV system regardless of the level and method of automation employed within it. 


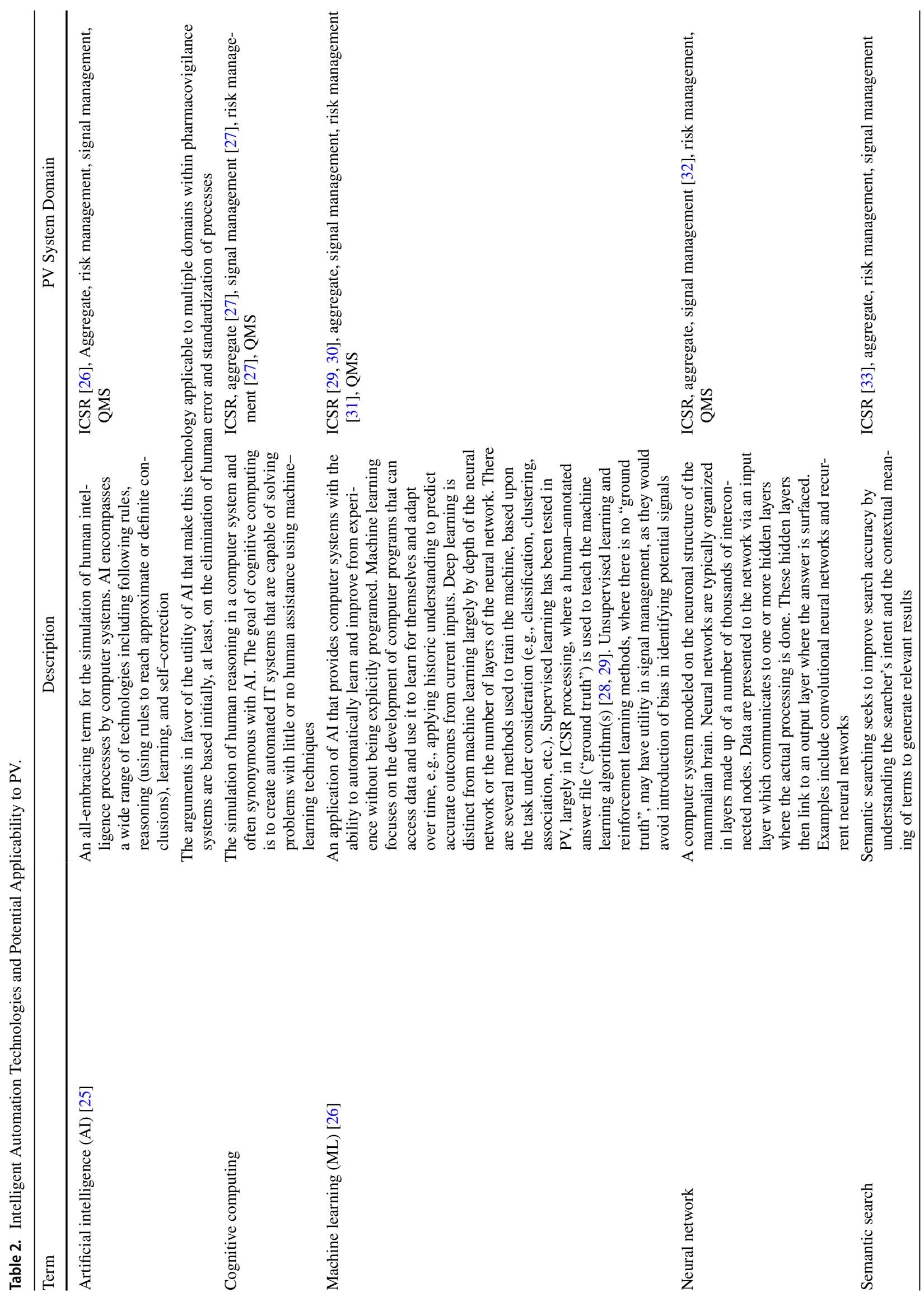




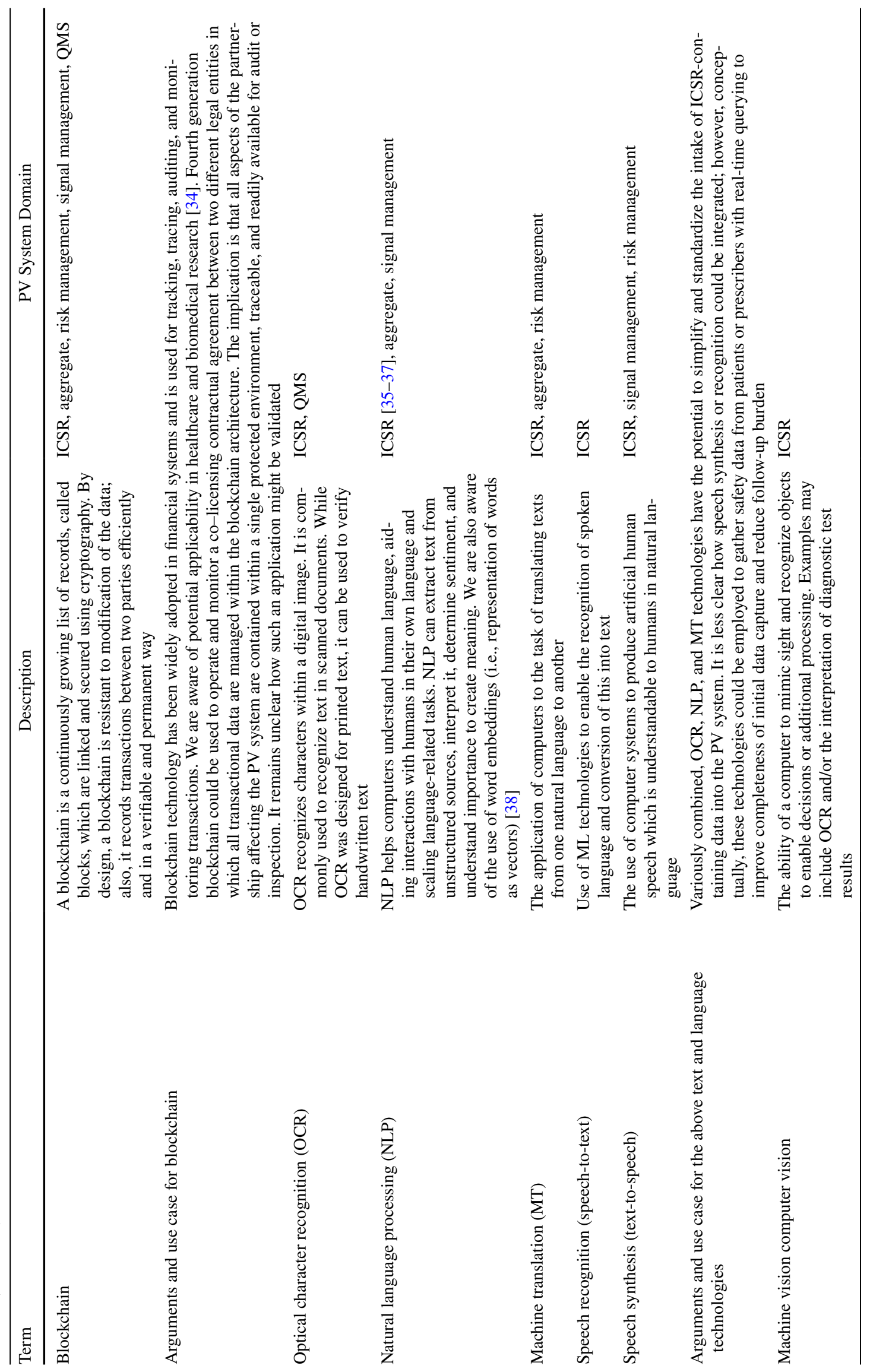




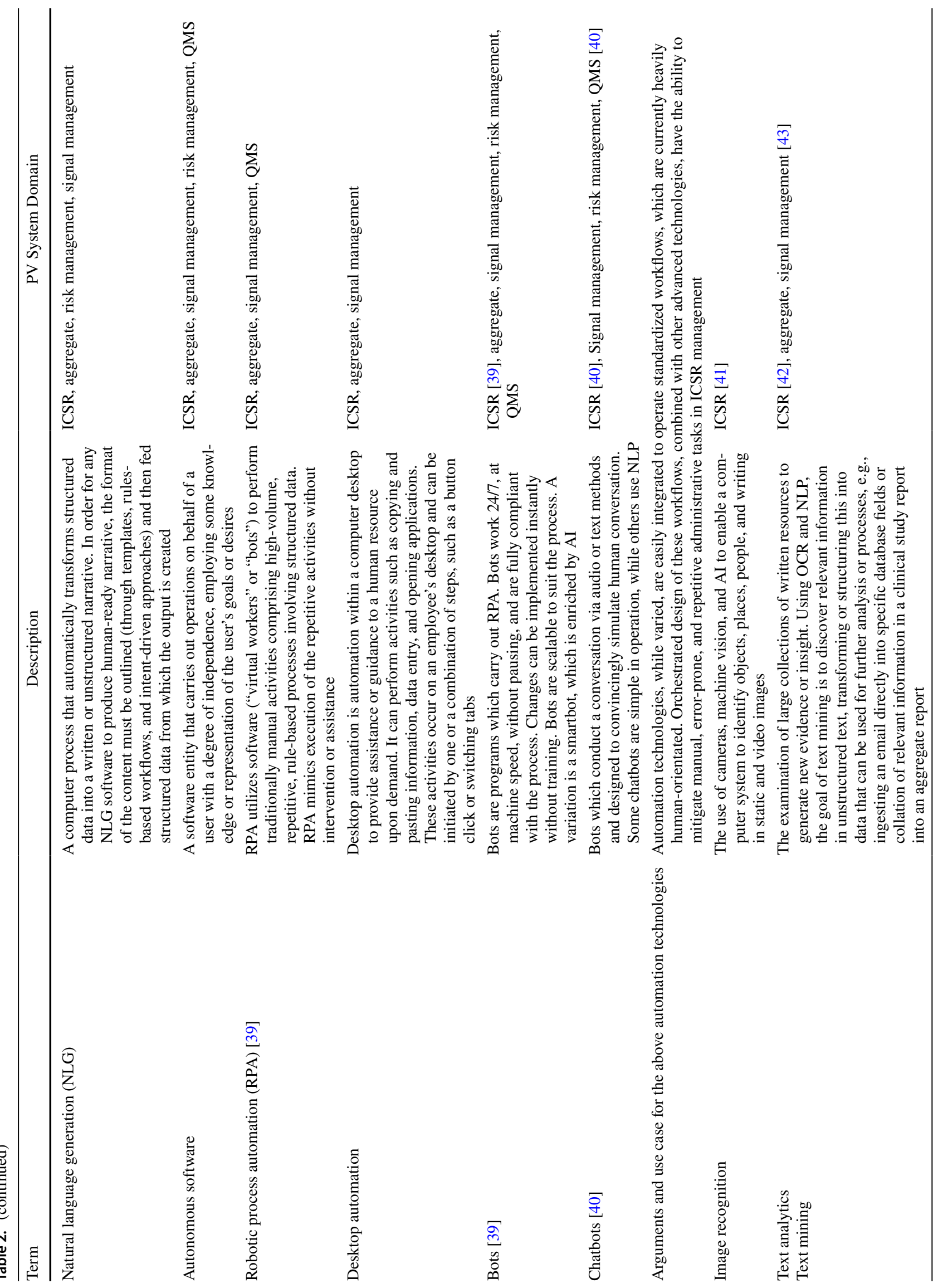




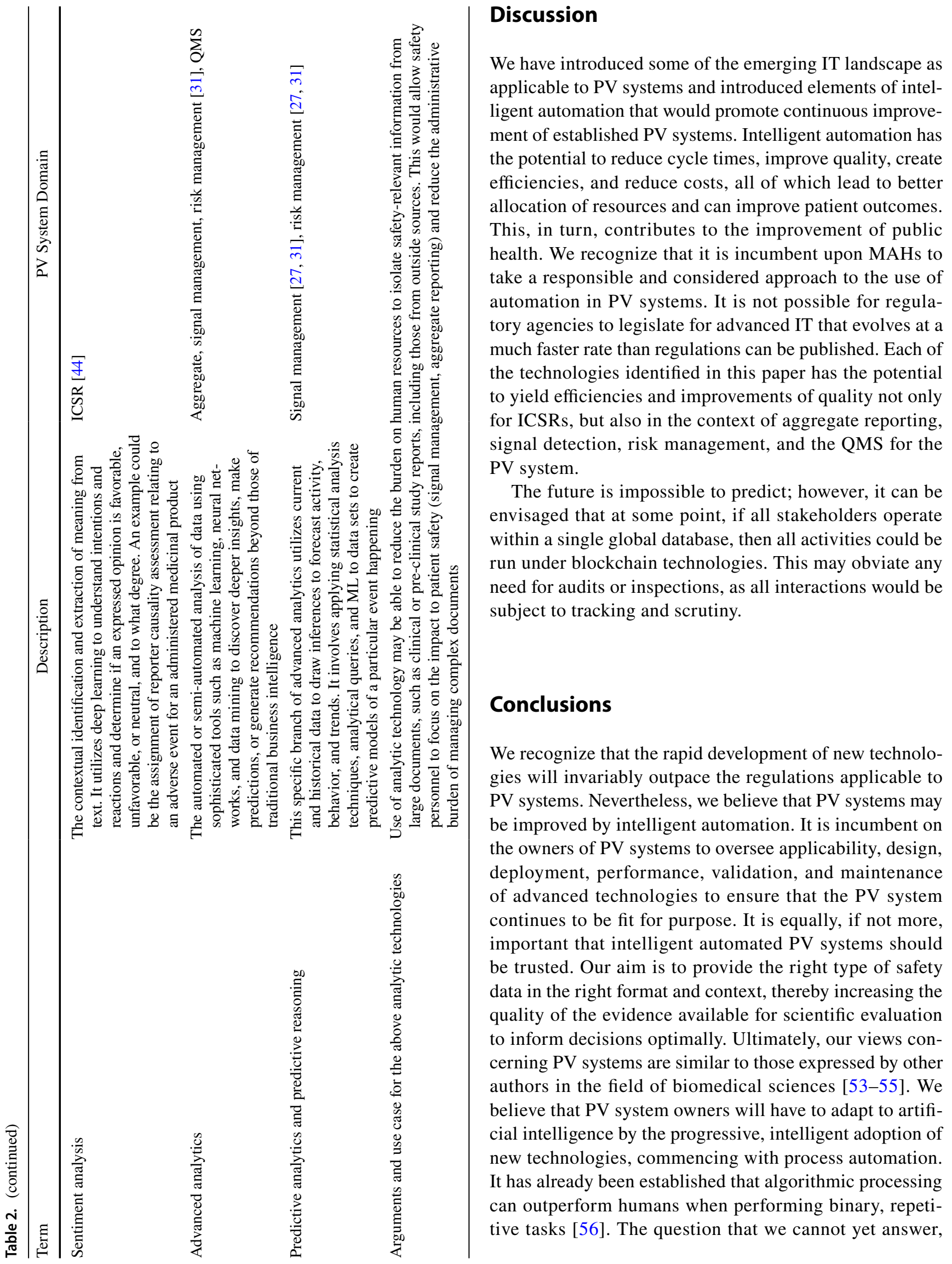


is exactly how far data-driven, high-performance PV can be taken by intelligent automation? Further, the evolution of $\mathrm{PV}$ in recent years along with the increasing volume of generated and gathered data point to the importance of adopting more advanced technologies that will not only automate but also improve the overall process. If we paraphrase Turing's original hypothesis from $19[50,57]$ then, provided we establish what are proven facts in PV systems, then the conjectures that may result from the intelligent use of AI are of potentially great importance because they suggest useful lines of research.

\section{Acknowledgements}

The authors worked as part of the TransCelerate Biopharma Inc. consortium which is funded by 20 organizations dedicated to making research and development, including pharmacovigilance monitoring and reporting, more efficient and effective in the pharmaceutical industry. We acknowledge contributions from Renee Urcioli for project management support, Kristof Huysentruyt, Ken Kubota, Eileen Leonard, and Jürgen Schmider. We also wish to thank Dr Howard Snow at Novartis for review and improvements to the manuscript.

\section{Funding}

No funding sources were provided to the authors.

\section{Compliance with Ethical Standards}

\section{Conflict of interest}

The authors declare no conflicts of interest. However, all authors are employees and/or stockholders of the companies with which they are affiliated.

Open Access This article is licensed under a Creative Commons Attribution 4.0 International License, which permits use, sharing, adaptation, distribution and reproduction in any medium or format, as long as you give appropriate credit to the original author(s) and the source, provide a link to the Creative Commons licence, and indicate if changes were made. The images or other third party material in this article are included in the article's Creative Commons licence, unless indicated otherwise in a credit line to the material. If material is not included in the article's Creative Commons licence and your intended use is not permitted by statutory regulation or exceeds the permitted use, you will need to obtain permission directly from the copyright holder. To view a copy of this licence, visit http://creativecommons.org/licenses/by/4.0/.

\section{References}

1. European Medicines Agency (EMA). Guideline on good pharmacovigilance practices (GVP) annex i-definitions (EMA/876333/2011 Rev 4). 2017. https://www.ema.europa.eu/ en/documents/scientific-guideline/guideline-good-pharmacovi gilance-practices-annex-i-definitions-rev-4_en.pdf. Accessed 19 Feb 2019.
2. European Commission. Commission Implementing Regulation (EU) No. 520/2012. Official Journal of the European Union. 2012. https://eur-lex.europa.eu/LexUriServ/LexUriServ.do?uri=OJ:L:2 012:159:0005:0025:en:pdf. Accessed 19 Feb 2019.

3. US Food and Drug Administration (FDA). Expedited safety reporting requirements for human drug and biological products. 2015. https://www.fda.gov/ScienceResearch/SpecialTopics/Runni ngClinicalTrials/ucm120262.htm. Accessed 19 Feb 2019.

4. European Medicines Agency (EMA). EMA/873138/2011 Rev 2Guideline on good pharmacovigilance practices (GVP). Module VI-collection, management and submission of reports of suspected adverse reactions to medicinal products. 2017. http://www. ema.europa.eu/docs/en_GB/document_library/Regulatory_and procedural_guideline/2017/08/WC500232767.pdf. Accessed 18 Mar 2019.

5. Postigo R, Brosch S, Slattery J, et al. Eudravigilance medicines safety database: publicly accessible data for research and public health protection. Drug Saf. 2018;4:665-75.

6. Pacurariu AC, Coloma PM, van Haren A, Genov G, Sturkenboom MC, Straus SM. A description of signals during the first 18 months of the EMA pharmacovigilance risk assessment committee. Drug Saf. 2014;37(12):1059-66. https://doi.org/10.1007/ s40264-014-0240-1.

7. European Parliament. Regulation (EU) No 536/2014 on clinical trials on medicinal products for human use. 2014. https://ec.europ a.eu/health/human-use/clinical-trials/regulation_en. Accessed 19 Feb 2019.

8. US Code of Federal Regulations. 21 CFR 312.32-IND safety reporting. Washington DC: US Government Publishing Office; 2010. https://www.govinfo.gov/app/details/CFR-2011-title 21-vol5/CFR-2011-title21-vol5-sec312-32. Accessed 18 Mar 2019.

9. International Council for Harmonisation (ICH). Harmonised tripartite guideline: clinical safety data management: definitions and standards for expedited reporting E2A. 1994. https://www.ich.org/ fileadmin/Public_Web_Site/ICH_Products/Guidelines/Efficacy/ E2A/Step4/E2A_Guideline.pdf. Accessed 28 July 2019.

10. European Medicines Agency (EMA). ICH guideline E2B (R3) on electronic transmission of individual case safety reports (ICSRs) - data elements and message specification —implementation guide. 2013. https://www.ema.europa.eu/en/documents/scien tific-guideline/international-conference-harmonisation-technicalrequirements-registration-pharmaceuticals-human-use_en-4.pdf. Accessed 28 July 2019.

11. International Council for Harmonisation (ICH). Harmonised tripartite guideline: medical dictionary for regulatory activities. 1997. https://www.ich.org/products/guidelines/multidisciplinary/ article/multidisciplinary-guidelines.html. Accessed 28 July 2019.

12. OHDSI Collaborative. Large-scale adverse effects related to treatment evidence standardization (LAERTES): an open scalable system for linking pharmacovigilance evidence sources with clinical data. J Biomed Seman. 2017;8:1-15.

13. TransCelerate. Intelligent automation opportunities in pharmacovigilance. https://transceleratebiopharmainc.com/initiative s/intelligent-automation-opportunities-pharmacovigilance/. Accessed 09 Oct 2019.

14. European Parliament and the Council of Europe. Directive 2010/84/EU. 2010. https://eur-lex.europa.eu/LexUriServ/LexUr iServ.do?uri=OJ:L:2010:348:0074:0099:EN:PDF. Accessed 28 July 2019.

15. European Commission. Implementing Regulation (EU) 520/2012. 2012. https://eur-lex.europa.eu/LexUriServ/LexUriServ.do?uri= OJ:L:2012:159:0005:0025:EN:PDF. Accessed 28 July 2019.

16. Godlee F. Wakefield's article linking MMR vaccine and autism was fraudulent. BMJ. 2011;342:7452. https://doi.org/10.1136/bmj. c7452. 
17. WHO. Minimum Requirements for a functional pharmacovigilance system. 2010. https://www.who.int/medicines/areas/quali ty_safety/safety_efficacy/PV_Minimum_Requirements_2010_2. pdf. Accessed 15 Aug 2019.

18. European Medicines Agency (EMA). Guideline on good pharmacovigilance practices (GVP) module I-pharmacovigilance systems and their quality systems. 2012. https://www.ema.europ a.eu/en/documents/scientific-guideline/guideline-good-pharm acovigilance-practices-module-i-pharmacovigilance-systems-their -quality-systems_en.pdf. Accessed 28 July 2019.

19. European Medicines Agency (EMA). Guideline on good pharmacovigilance practices (GVP) module $\mathrm{V}$-risk management systems (Revision 2). 2017. https://www.ema.europa.eu/en/docum ents/scientific-guideline/guideline-good-pharmacovigilance-pract ices-module-v-risk-management-systems-rev-2_en.pdf. Accessed 28 July 2019.

20. European Medicines Agency (EMA). Guideline on good pharmacovigilance practices (GVP) module VI-collection, management and submission of reports of suspected adverse reactions to medicinal products (Revision 2). 2017. https://www. ema.europa.eu/en/documents/regulatory-procedural-guideline/ guideline-good-pharmacovigilance-practices-gvp-module-vicollection-management-submission-reports_en.pdf. Accessed 28 July 2019.

21. European Medicines Agency (EMA). Guideline on good pharmacovigilance practices (GVP) module VII-periodic safety update report (Rev 1). 2013. https://www.ema.europa.eu/en/documents/ scientific-guideline/guideline-good-pharmacovigilance-practicesgvp-module-vii-periodic-safety-update-report_en.pdf. Accessed 28 July 2019.

22. European Medicines Agency (EMA). Guideline on good pharmacovigilance practices (GVP) module IX — signal management (Revision 1). 2017. https://www.ema.europa.eu/en/documents/ scientific-guideline/guideline-good-pharmacovigilance-pract ices-gvp-module-ix-signal-management-rev-1_en.pdf. Accessed 28 July 2019

23. National Institute for Science and Technology. Information technology: artificial intelligence. https://www.nist.gov/topics/artif icial-intelligence. Accessed 18 Mar 2019.

24. European Commission. Horizon 2020: Information and Communication Technologies. https://ec.europa.eu/programmes/horiz on2020/en/h2020-section/information-and-communication-techn ologies. Accessed 18 Mar 2019.

25. McCarthy, J. What is artificial intelligence? 2007. http://jmc.stanf ord.edu/articles/whatisai/whatisai.pdf. Accessed 1 Aug 2019.

26. US Food and Drug Administration (FDA). Artificial intelligence and machine learning in software as a medical device. 2019. https ://www.fda.gov/media/122535/download. Accessed 1 Aug 2019.

27. Chen Y, Argentinis E, Weber G. IBM Watson: how cognitive computing can be applied to big data challenges in life sciences research. Clin Ther. 2016;38(4):688-701. https://doi. org/10.1016/j.clinthera.2015.12.001.

28. Comfort S, Perera S, Hudson Z, et al. Sorting through the safety data haystack: using machine learning to identify individual case safety reports in social-digital media. Drug Saf. 2018;41(6):579_ 90. https://doi.org/10.1007/s40264-018-0641-7.

29. Sloan R, Osanlou O, Lewis D, Bollegala D, Maskell S, Pirmohamed M. Social media and pharmacovigilance: a review of the opportunities and challenges. $\mathrm{Br} \mathrm{J}$ Clin Pharmacol. 2015;80(4):910-20. https://doi.org/10.1111/bcp.12717.

30. Liu J, Zhao S, Wang G. SSEL-ADE: a semi-supervised ensemblelearning framework for extracting adverse drug events from social media. Artif Intell Med. 2017;84:34-49. https://doi.org/10.1016/j. artmed.2017.10.003.

31. Thomasev N, Glorot X, Rae GW, et al. A clinically applicable approach to continuous prediction of future acute kidney injury.
Nature. 2019;572(7767):116-9. https://doi.org/10.1038/s4158 6-019-1390-1.

32. Bate A, Lindquist M, Edwards IR, et al. A Bayesian neural network method for adverse drug reaction signal generation. Eur $J$ Clin Pharmacol. 1998;54:315-21.

33. Ben Abacha A, Zweigenbaum, P. A hybrid approach for the extraction of semantic relations from MEDLINE abstracts. In: 12th International Conference on Computational Linguistics and Intelligent Text Processing, CICLing 2011, Tokyo, Japan; 2011. https://rd.springer.com/chapter/10.1007/978-3-642-19437-5_11. Accessed 10 Aug 2019.

34. Mamoshina P, Ojomoko L, Yanovich Y, Ostrovski A, Botezatu A, Prikhodko P, Izumchenko E, Aliper A, Romantsov K, Zhebrak A, Ogu IO. Converging blockchain and next-generation artificial intelligence technologies to decentralize and accelerate biomedical research and healthcare. Oncotarget. 2018;9(5):5665.

35. Segura-Bedmar I, Martinez P. Pharmacovigilance through the development of text mining and natural language processing techniques. J Biomed Inform. 2015;58:288-91. https://doi. org/10.1016/j.jbi.2015.11.001.

36. Wong A, Plasek JM, Montecalvo SP, Zhou L. Natural language processing and its implications for the future of medication safety: a narrative review of recent advances and challenges. Pharmacotherapy. 2018;38(8):822-41.

37. Bollegala D, Maskell S, Sloane R, Hajne J, Pirmohamed M. Causality patterns for detecting adverse drug reactions from social media: text mining approach. JMIR Public Health Surveill. 2018;4(2):e51.

38. Mikolov T, Sutskever I, Chen K, Corrado GS, Dean J. Distributed representations of words and phrases and their compositionality. In: Advances in neural information processing systems; 2013. p. 3111-3119.

39. Ernst and Young. How robotics is reshaping the biopharma value chain. 2018. https://www.ey.com/Publication/vwLUAssets/eyhow-robotics-is-reshaping-the-biopharma-value-chain/\$FILE/ ey-how-robotics-is-reshaping-the-biopharma-value-chain.pdf. Accessed 1 Aug 2019.

40. Nath J. Chatbot, machine learning and artificial intelligence in pharmacovigilance: maintaining privacy, optimizing efficiency. Chatbots Magazine. May 2018. https://chatbotsmagazine.com/ chatbot-machine-learning-and-artificial-intelligence-in-pharm acovigilance-maintaining-privacy-877283e4b4b7. Accessed 1 Aug 2019.

41. Facial Dysmorphology Novel Analysis (FDNA). How it works. https://www.face2gene.com/technology-facial-recognition-featu re-detection-phenotype-analysis/. Accessed 1 Aug 2019.

42. Fong A, Hettinger AZ, Ratwani RM. Exploring methods for identifying related patient safety events using structured and unstructured data. J Biomed Inform. 2015. https://doi.org/10.1016/j. jbi.2015.09.011.

43. Yang M, Kiang M, Shang W. Filtering big data from social media: building an early warning system for adverse drug reactions. $J$ Biomed Inform. 2015;54:230-40. https://doi.org/10.1016/j. jbi.2015.01.011.

44. Rajalakshmi P, Rajagopalan SP. Sentiment ontology analysis in pharmacovigilance. IJECS. 2017;6:22567-79.

45. European Commission. General data protection regulation (GDPR) 2016/679. 2016. https://eur-lex.europa.eu/legal-content/ EN/TXT/?uri=celex\%3A32016R0679. Accessed 18 Mar 2019.

46. UK Parliament. UK Data Protection Act 2018. 2018. https://www. legislation.gov.uk/ukpga/2018/12/schedule/19. Accessed 20 Mar 2019.

47. Grace K, Salvatier J, Dafoe A, Zhang B, Evans O. When will AI exceed human performance? Evidence from AI experts. Updated 2018. https://arxiv.org/abs/1705.08807. Accessed 18 Mar 2019. 
48. Beam AL, Kohane IS. Translating artificial intelligence into clinical care. JAMA. 2016;316(22):2368-9. https://doi.org/10.1001/ jama.2016.17217.

49. Zaidi D. AI is transforming medical diagnosis, prosthetics and vision aids. Venture Beat. 2017. https://venturebea t.com/2017/10/30/ai-is-transforming-medical-diagnosis-prost hetics-and-vision-aids/. Accessed 18 Mar 2019.

50. Zitnik M, Nguyen F, Wang B, Leskovec J, Goldenberg A, Hoffman MM. Machine learning for integrating data in biology and medicine, principles, practice, and opportunities. Inf Fusion. 2018;50:71-91. https://doi.org/10.1016/j.inffus.2018.09.012.

51. Yu KH, Beam AL, Kohane IS. Artificial intelligence in healthcare. Nat Biomed Eng. 2018;2:719-31.

52. Danysz K, Cicirello S, Mingle E, et al. Artificial intelligence and the future of the drug safety professional. Drug Saf. 2018;42(4):491-7. https://doi.org/10.1007/s40264-018-0746-z.

53. Schmider J, Kumar K, LaForest C, Swankoski B, Naim K, Caubel PM. Innovation in pharmacovigilance: use of artificial intelligence in adverse event case processing. Clin Pharmacol Ther. 2018;105(4):954-61. https://doi.org/10.1002/cpt.1255.

54. Jha S, Topol EJ. Adapting to artificial intelligence: radiologists and pathologists as information specialists. JAMA. 2016;316(22):2353-4. https://doi.org/10.1001/jama.2016.17438.

55. Fogel AL, Kvedar JC. Artificial intelligence powers digital medicine. NPJ Digital Med. 2018;1(1):1-4. https://doi.org/10.1038/ s41746-017-0012-2.

56. Topol EJ. High-performance medicine: the convergence of human and artificial intelligence. Nat Med. 2019;25:44-56.

57. Turing AM. Computing machinery and intelligence. Mind. 1950;9:433-60.

Publisher's Note Springer Nature remains neutral with regard to jurisdictional claims in published maps and institutional affiliations. 